\title{
EVALUASI PELAKSANAAN PROGRAM KELUARGA HARAPAN (PKH) DI NAGARI TANJUANG BUNGO KECAMATAN SULIKI KABUPATEN LIMAPULUH KOTA
}

\author{
oleh : \\ Wenny Desty Febrian \\ Zulhaida \\ Abdiana Ilosa \\ Dosen UIN Suska Riau
}

\begin{abstract}
ABSTRAK
Tujuan dari penelitian ini adalah untuk mengetahui 1) Bagaimana evaluasi pelaksanaan Program Keluarga Harapan (PKH) di Nagari Tanjuang Bungo Kecamatan Suliki Kabupaten Limapuluh Kota. 2)Faktor-faktor hambatan dalam Pelaksanaan Program Keluarga Harapan (PKH) Di Nagari Tanjuang Bungo Kecamatan Suliki Kabupaten Lima Puluh Kota. Jenis penelitian ini penelitian kualitatif. Indikator yang digunakan dalam penelitian ini yaitu 1). Efekivitas pelaksanaan Program Keluarga Harapan (PKH) 2) Pemerataan Penetapan Penerima Manfaat (KPM) Program Keluarga Harapan (PKH) 3) Resposivitas dari Keluarga Penerima Manfaat PKH. Dari penelitian dapat disimpulkan bahwa pelaksanaan Program Keluarga Harapan di Nagari Tanjuang Bungo Kecamatan Suliki Kabupaten Limapuluh Kota sudah berjalan dengan cukup baik walaupun belum optimal dalam segi penetapan Keluarga Penerima Manfaat (KPM) Program Keluarga Harapan (PKH) sehingga banyak masyarakat yang seharusnya mendapatkan bantuan PKH tetapi tidak mendapatkan bantuan. Dalam pelaksanaan Program Keluarga Harapan (PKH) di Nagari Tanjuang Bungo Kecamatan Suliki Kabupaten Limapuluh Kota terdapat beberapa hambatan yaitu tidak adanya pendamping yang intens mendampingi para peserta sehingga dana Program Keluarga Harapan (PKH) dibelanjakan di luar ketentuan yang dipersyaratkan, jauhnya jarak tempat tinggal pendamping yang berada di luar Wilayah dan tidak adanya jaringan telepon seluler di Nagari Tanjuang Bungo menyulitkan proses monitoring dan komunikasi yang harus dilakukan pendamping kepada Keluarga Penerima Manfaat (KPM) Program Keluarga Harapan (PKH)
\end{abstract}

Kata Kunci :Evaluasi, Kebijakan Publik, Efektivitas, Pemerataan, Responsifitas,Program Keluarga Harapan

\section{Latar Belakang}

Kemiskinan di Indonesia bukan hal yang baru dilihat dan didengar, angka kemiskinan di Indonesia masih tergolong tinggi dibandingkan negara tetangga maupun di Asia. Bermacam-macam program telah dilakukan pemerintah untuk menanggulangi angka kemiskinan dinegara ini, namun hal ini sepertinya tidak kunjung berkesudahan. Kemiskinan merupakan fenomena global yang sangat memprihatinkan, dari tahun ketahun masalah kemiskinan ini tidak kunjung surut bahkan cenderung meningkat seiring dengan meningkatnya kebutuhan masyarakat serta menurunnya kondisi perekonomian Negara Indonesia.

Nazara dalam Nurwati (2008:5) mengemukakan lima faktor yang dianggap dapat mempengaruhi terjadinya kemiskinan, yaitu: (1) pendidikan; (2) jenis pekerjaan; (3) gender; (4) akses terhadap pelayanan kesehatan dasar; dan (5) infrastruktur dan lokasi geografis. Faktor-faktor tersebut ada keterkaitan satu sama lainnya yang membentuk lingkaran kemiskinan.

Rumah tangga miskin pada umumnya terpusat di daerah pedesaan dan berpendidikan rendah. Rendahnya tingkat pendidikan menyebabkan produktivitas penduduk turut rendah sehingga imbalan yang akan diperoleh tidak memadai untuk memenuhi kebutuhan pangan, sandang, kesehatan, perumahan, dan pendidikan. Akibatnya, rumah tangga miskin akan menghasilkan keluarga- keluarga miskin pula pada generasi berikutnya.

Kemiskinan merupakan masalah yang padaumumnyadihadapihampirdi semuanegara-negara berkembang, terutama negarayang padatpenduduknya sepertiIndonesia.Badan Pusat Statistik (BPS) mencatat Indonesia mengalami titik terendah dalam hal persentase kemiskinan sejak tahun 1999, yakni sebesar 9,82\% pada Maret 2018. Dengan persentase kemiskinan 9,82\%, jumlah penduduk miskin atau yang pengeluaran per kapita tiap bulan di bawah garis kemiskinan mencapai 25,95 juta 
orang. Jika dibandingkan dengan periode sebelumnya, yaitu September 2017, persentase kemiskinan tercatat sebesar $10,12 \%$ atau setara dengan 26,58 juta orang penduduk miskin di Indonesia. Terdapat penurunan persentase penduduk miskin baik di perkotaan maupun di perdesaan. Persentase penduduk miskin di perkotaan per Maret 2018 sebesar 7,02\%, turun dibandingkan September 2017 sebesar $7,26 \%$. Sama halnya dengan di perdesaan, di mana persentasenya pada Maret 2018 sebesar 13,20\%, turun dari posisi September 2017 sebesar 13,47\%.

Adapun program-program Nasional pengentasan kemiskinan yang telah dilakukan oleh Indonesia dan turut di implementasikan di daerah salah satunya yaitu di Kecamatan Suliki Kabupaten Limapuluh Kota yaitu meliputi :

1. Kategori I yaitu Program Bantuan dan Perlindungan Sosial.

Termasuk dalam kategori I adalah Program Beras Miskin (Raskin), Program Keluarga

Harapan (PKH), Program Jaminan Kesehatan Masyarakat (Jamkesmas) dan Program Beasiswa.

2. Kategori II yaitu Program Pemberdayaan Masyarakat (PNPM).

Termasuk dalam Program II ini adalah PNPM Pedesaan (PPK), PNPM Perkotaan (P2KP), PNPM Infrastruktur Pedesaan (PPIP), PNPM Kelautan (PEMP) dan PNPM Agribisnis (PUAP).

3. Kategori III yaitu Program Pemberdayaan Usaha Kecil Menengah (UKM).

Termasuk di dalamnya Program Kredit UMKM dan Program Kredit Usaha Rakyat (KUR).

Dengan kondisi demikian, maka negara berkewajiban untuk melakukan upaya pengentasan kemiskinan, dan meningkatkan kesejahteraan masyarakatnya, karena masyarakat miskin merupakantanggung jawab negara Indonesia. Sebagaimana tertuang dalam UUD 1945 Pasal 34 ayat 1 yang berbunyi, "Fakir miskin dan anak- anak terlantar dipelihara oleh negara". Dalam rangka melaksanakankewajiban negara tersebut, maka Pemerintah Indonesia harus memberikan perhatiannya secara serius dalam menanggulangi masalah kemiskinan dan perlu membuat suatu kebijakan atau program nasional yang berkaitan dengan pertumbuhan kesejahteraan masyarakat secara adil dan rata.

Kesehatan ibu mengandung

Kesehatan anak balita

\section{Tingkat Kesehatan}
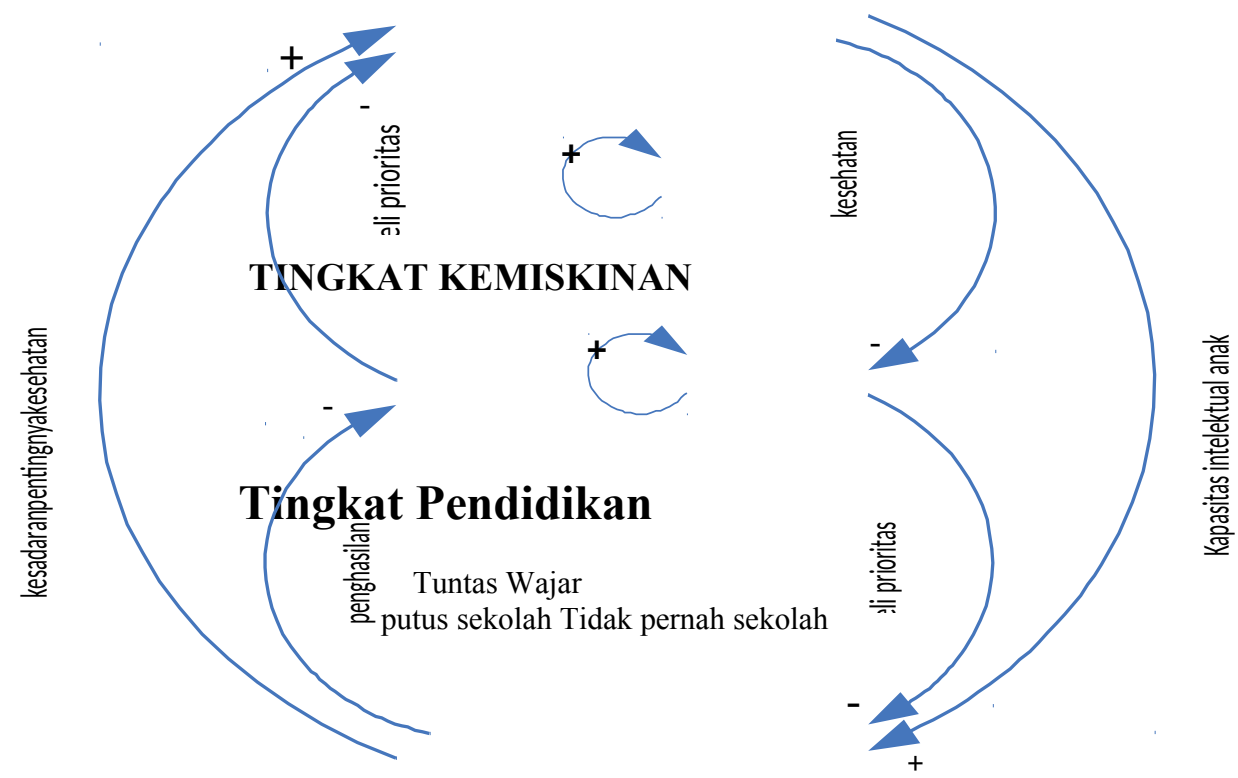


\title{
Gambar 1. LingkaranKemiskinan
}

\author{
Sumber: Pedoman Umum PKH,2013
}

Berdasarkan gambar di atas menunjukkan bahwa tingkat kemiskinan suatu rumah tangga secara umum terkait dengan tingkat pendidikan dan kesehatan. Rendahnya penghasilan keluarga sangat miskin menyebabkankeluarga tersebut tidak mampu memenuhi kebutuhan akan fasilitas pendidikan dan kesehatan. Pemeliharaan kesehatan ibu sedang mengandung pada keluarga sangat miskin sering tidak memadai sehingga menyebabkan buruknya kondisi kesehatan bayi yang dilahirkan atau menimbulkan dampak yang lebih besar berupa kematian bayi. Selanjutnya, di bidang pendidikan masalah kemiskinan berdampak pada bertambahnya jumlah anak putus sekolah dari keluarga miskin.

Dalam pelaksanaan semua kebijakan ataupun program yang dikeluarkan pemerintah, pasti ada dasar hukumnya, pedoman pelaksanaan atau dasar hukum PKH di Nagari Tanjuang Bungo Kec. Suliki Kabupaten Limapuluh Kota didasari atas beberapa peraturan yang berlaku, diantaranya adalah sebagai berikut :

1. PMK No.228/PMK/.05/2016 tentang Perubahan Atas PMK No. 254/PMK.05/2015 Tentang Belanja Bantuan Sosial Pada Kementerian Negara/ Lembaga

2. Permensos No.1 Tahun 2018 tentang Pelaksanaan Program Keluarga Harapan

3. Peraturan Presiden No. 63 Tahun 2017 tentang Penyaluran Bantuan Sosial Non Tunai

4. SK Dirjen Nomor 12/LJS.SET.OHH/09/2016 tentang Pedoman Umum PKH.

Denganadanya program keluarga harapan ini maka penulis tertarik untuk melakukan penelitian di Nagari Tanjuang Bungo Kecamatan Suliki Kabupaten Limapuluh Kota, karena masih banyaknya masyarakat miskin, anak-anak yang putus sekolah disebabkan terkendala biaya dan juga di Nagari Tanjuang Bungo masyarakat masih sulit mendapatkan layanan kesehatan.Jumlah penduduk di Nagari Tanjuang Bungo berjumlah 1443 jiwa, terdiri dari $440 \mathrm{KK}$ dan $138 \mathrm{KK}$ diantaranya tergolong miskin, berarti $31,36 \%$ penduduk di Nagari tanjuang tergolong miskin.

Sasaran Program Keluarga Harapan (PKH) di Nagari Tanjuang Bungo Kecamatan Suliki Kabupaten Limapuluh Kota merupakan keluarga atau seseorang yang miskin dan rentan yang memiliki komponen kesehatan, pendidikan dan kesejahteraan sosial.

1. Kriteria Komponen Kesehatan meliputi :

a. Ibu hamil/ menyusui

b. Anak berusia 0 (nol) sampai dengan 6 (enam) tahun

2. Komponen Pendidikan meliputi :

a. Anak Sekolah Dasar/Madrasah Ibtidaiyah atau sederajat

b. Anak Sekolah Menengah Pertama/Madrasah Tsanawiyah atau sederajat

c. Anak Sekolah Menengah Atas/Madrasah Aliyah atau sederajat

d. Anak usia 6 (enam) sampai dengan 21 (dua puluh satu) tahun yang belum menyelesaikan wajib belajar 12 (dua belas) tahun

3. Komponen Kesejahteraan Sosial

a. Lanjut usia mulai dari 60 (enam puluh) tahun

b. Penyandang disabilitas

Adapun jumlah pemohon untuk bantuan Program Keluarga Harapan (PKH) yang memiliki komponen (Kesehatan, Pendidikan dan Kesejahteraan Sosial) danjumlah keluarga yang mendapat bantuan PKH di Nagari Tanjuang Bungo Kecamatan Suliki Kabupaten Limapuluh Kota yang terdapat pada table berikut:

\section{Tabel 1}


Pemohon Bantuan dan KeluargaPenerima Manfaat PKH di Nagari TanjuangBungo Tahun2018

\begin{tabular}{|c|c|c|}
\hline Alamat(Jorong) & Pemohon Bantuan PKH & $\begin{array}{c}\text { Keluarga Penerima Manfaat } \\
\text { PKH }\end{array}$ \\
\hline Batang Linjuang & 29 & 12 \\
\hline Korek Hilia & 27 & 8 \\
\hline Kubu Tangah & 23 & 10 \\
\hline Lancaran & 19 & 6 \\
\hline JUMLAH & $\mathbf{9 8}$ & $\mathbf{3 6}$ \\
\hline
\end{tabular}

Sumber : Kantor Wali Nagari Tanjuang Bungo Kec. Suliki Kab. Limapuluh Kota

Masyarakat yang mendapatkan bantuan PKH di Nagari Tanjuang Bungo hanya berjumlah 36 KK, padahal jumlah pemohon yang membutuhkan bantuan PKH berjumlah $98 \mathrm{KK}$, masih jauh dari harapan padahal tidak ada ketentuan kuota yang ditetapkan mengenai jumlah peserta PKH, hasil wawancara dari salah seorang masyarakat Tanjuang Bungo, beliau mengatakan bahwa banyaknya masyarakat miskin yang tidak mendapatkan bantuan PKH disebabkan karna tidak memenuhi persyaratan untuk menjadi peseta PKH.

Adapun besaran bantuan yang diberikan kepada masyarakat miskin atau KPMpeserta Program Keluarga Harapan (PKH) mengikuti skenario bantuan yang disajikanpadatabelberikut:

Tabel 2

Skenario Besaran Bantuan PKH 2018

\begin{tabular}{|l|l|}
\hline Bantuan Tetap Setiap KPM & Rp. 500.000 / keluarga / tahun \\
\hline Bantuan Komponen : & \\
1. Ibu Hamil/Balita & Rp. $2.400 .000 /$ tahun \\
2. SD/Sederajat & Rp. $900.000 /$ tahun \\
3. SMP/Sederajat & Rp. $1.500 .000 /$ tahun \\
4. SMA/Sederajat & Rp. $2.000 .000 /$ tahun \\
5. Penyandang Disabilitas & Rp. $2.400 .000 /$ tahun \\
6. Lanjut Usia 60 tahun keatas & Rp. $2.400 .000 /$ tahun \\
\hline \multicolumn{2}{|l|}{ Maksimal 1 Orang Dalam Satu Keluarga } \\
\hline
\end{tabular}

Sumber : Kantor Wali Nagari Tanjuang Bungo Kec. Suliki Kab. Limapuluh Kota

Bantuan untuk komponen PKH di Nagari Tanjuang Bungo di salurkan melalui empat tahap, yaitu satu kali penerimaan dalam 3 bulan. Tahap pertama (Januari, Februari, Maret), tahap kedua (April, Mei, Juni), tahap ketiga (Juli, Agustus, September) dan sisanya diterima pada tahap keempat (Oktober, November, Desember.Adapun permasalahan yang ada di NagariTanjuang Bungo yang belum bisa teratasi adalah:

1. Belum meratanya penerimaan bantuan PKH. Hal ini terlihat dengan masih banyaknya Keluarga Miskin yang belum mendapatkan bantuan tersebut.

2. Kurangnya Transparansi mengenai pendataan awal calon-calon yang akan menerima bantuan Program Keluarga Harapan.

3. Kurangnya pengawasan mengenai Program Keluarga Harapan, sehingga ada keluarga yang sangat membutuhkan bantuan PKH tetapi tidak mendapatkan bantuan tersebut.

Berdasarkan uraian dan gejala yang ada maka disini penulis tertarik untuk mengadakan penelitian dengan judul:"EvaluasiProgram Keluarga Harapan (PKH) di Nagari Tanjuang Bungo Kecamatan Suliki Kabupaten Limapuluh Kota”.

\section{Rumusan Masalah} adalah :

Berdasarkan latar belakang di atas maka penulis merumuskan masalah dalam penelitian ini

1. Bagaimana Evaluasi Pelaksanaan Program Keluarga Harapan (PKH)Di Nagari Tanjuang Bungo Kecamatan Suliki Kabupaten Lima Puluh Kota?

2. Apa saja faktor-faktor hambatan Dalam Pelaksanaan Program Keluarga Harapan (PKH) Di Nagari Tanjuang Bungo Kecamatan Suliki Kabupaten Lima Puluh Kota?

\section{Tujuan Penelitian}


a. Untuk Mengetahui Evaluasi Program Keluarga Harapan (PKH) Di Nagari Tanjuang Bungo Kecamatan Suliki Kabupaten Lima Puluh Kota.

b. Untuk mengetahui faktor-faktor hambatan Dalam Pelaksanaan Program Keluarga Harapan (PKH) Di Nagari Tanjuang Bungo Kecamatan Suliki Kabupaten Lima Puluh Kota.

\section{Tinjauan tentang Kebijakan Publik Konsep Kebijakan Publik}

Secara etimologis, istilah kebijakan(policy) berasal dari bahasa Yunani, sanskerta, dan latin. Selanjutnya Dunn menerangkan bahwa akar kata dalam bahasa Yunani dan Sanskerta, yaitupolis (negara-kota) dan dikembangkan dalam bahasa latin menjadi politia(negara) dan akhirnya dalam bahasa Inggris policie, yang berarti menangani masalah-masalah public atau administrasi pemerintahan (Dunn dalamAnggara,2012:449).

Menurut Nasucha dalam Pasolong (2013:39), kebijakan public adalah kewenangan pemerintah dalam pembuatan suatu kebijakan yang digunakan kedalam perangkat peraturan hukum. Chandler dan Plano dalam Pasolong (2013:38) mengatakan bahwa kebijakan public adalah pemanfaatan yang strategis terhadap sumber-sumber daya yang ada untuk memecahkan masalah public atau pemerintahan.

Kemudian, Dunn dalam Pasolong (2013:39) berpendapat bahwa kebijakan public adalah suatu rangkaian pilihan-pilihan yang saling berhubungan yang dibuat oleh lembaga atau pejabat pemerintah pada bidang-bidang yang menyangkut tugas pemerintahan, seperti pertanahan keamanan, energi, kesehatan, pendidikan, kesejahteraan masyarakat, kriminalitas, perkotaan, dan lain-lain.

Pendapat lainnya menurut Anderson dalam Subarsono (2016:2), mendefinisikan kebijakan public sebagai kebijakan yang ditetapkan oleh badan-badan dan aparat pemerintah. Walaupun disadari bahwa kebijakan public dapat dipengaruhi oleh para aktor dan factor dari luar pemerintah. Definisi lainnya menurut Dye dalam Subarsono (2016:2), kebijakan public yaitu "apapun yang dipilih pemerintah untuk dilakukan atau tidak dilakukan (public policy is whatever government choose to do or not to do)". Konsep tersebut sangat luas karena kebijakan public mencakup sesuatu yang tidak dilakukan pemerintah di samping yang dilakukan pemerintah ketika menghadapi masalah publik.

Berdasarkan beberapa pendapat para ahli di atas, maka peneliti menyimpulkan bahwa kebijakan public adalah serangkaian tindakan yang dilakukan atau tidak dilakukan oleh pemerintah yang berorientasi pada tujuan tertentu guna memecahkan masalah-masalah public atau demi kepentingan publik.

\section{Konsep Evaluasi}

Menurut Subarsono (2016:119), evaluasi adalah kegiatan untuk menilai tingkat kinerja suatu kebijakan. Rossi \& Freeman dalam Pasolong (2013:6) juga mengungkapkan bahwa evaluasi digunakan untuk mempelajari tentang hasil yang diperoleh dalam suatu program untuk dikaitkan dengan pelaksanannya, mengendalikan tingkah laku dari orang-orang yang bertanggung jawab terhadap pelaksanaan program, dan mempengaruhi respon dari mereka yang berada diluar lingkungan politik.

\section{Tujuan Evaluasi}

Menurut Subarsono (2016:120-122), evaluasi memiliki beberapa tujuan yang dapat dirinci sebagai berikut:

1) Menentukan tingkat kinerja suatu kebijakan. Melalui evaluasi maka dapat diketahui derajad pencapaian tujuan dan sasarankebijakan.

2) Mengukur tingkat efisiensi suatu kebijakan. Dengan evaluasi juga dapat diketahui berapa biaya dan manfaat dari suatukebijakan.

3) Mengukur tingkat keluaran (outcome) suatu kebijakan. Salah satu tujuan evaluasi adalah mengukur berapa besar dan kualitas pengeluaran atau output dari 
suatukebijakan.

4) Mengukur dampak suatu kebijakan. Pada tahap ini lebih lanjut, evaluasi ditujukan untuk melihat dampak positif maupunnegatif.

5) Untuk mengetahui apabila ada penyimpangan. Evaluasi juga bertujuan untuk mengetahui adanya penyimpangan-penyimpangan yang mungkin terjadi, dengan cara membandingkan antara tujuan dan sasaran pencapaiantarget.

6) Sebagaibahanmasukan(input)untukkebijakanyangakandatang.

Tujuan akhir dari evaluasi adalah untuk memberikan masukan bagi proses kebijakan kedepan agar dihasilkan kebijakan lebihbaik

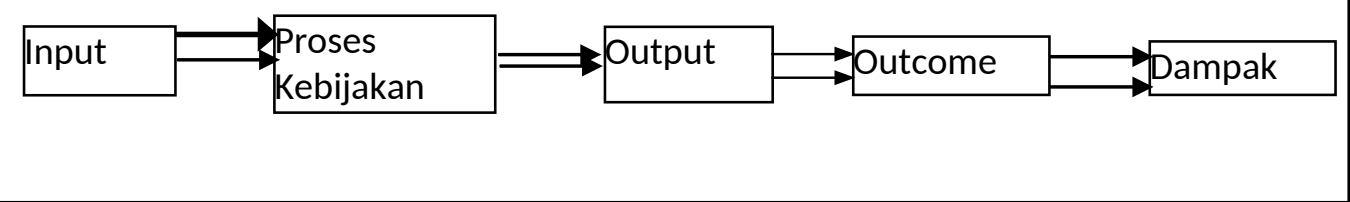

Umpan balik

Gambar 2. KebijakanSebagaiSebuah Proses

1. Input adalah bahan baku (raw materials) yang digunakan sebagai masukan dalam sebuah sistem kebijakan. Input tersebut berupa sumberdaya manusia, sumberdaya finansial, tuntutan-tuntatan, dukunganmasyarakat.

2. Sistem politik melalui para aktornya melakukan proses konversi dari input menjadi ouput. Selama proses konversi ini terjadi bargaining dan negosiasi antar para aktor yang berkepentingan yang mungkin berbeda atau bisasama.

3. Output adalah keluaran dari sebuah sistem kebijakan, yang dapat berupa peraturan, kebijakan, pelayanan/jasa, danprogram.

4. Sedangkan outcome adalah hasil suatu kebijakan dalam jangka waktu tertentu sebagai akibat diimplementasikannya suatukebijakan.

5. Impact (dampak) adalah akibat lebih jauh pada masyarakat sebagai konsekuensi adanya kebijakan diimpelementasikan.

\section{Alasan Evaluasi Kebijakan}

Evaluasi sangat diperlukan untuk keperluan jangka panjang dan untuk kepentingan keberlanjutan (sustainable) suatu program. Subarsono (2016:123-124) memberikan beberapa argument perlunya evaluasi.

1. Untuk mengetahui tingkat efektivitas suatu kebijakan, yakni seberapa jauh suatu kebijakan mencapaitujuannya

2. Mengetahui apakah suatu kebijakan berhasil atau gagal. Dengan melihat tingkat efektivitasnnya, maka dapat disimpulkan apakah suatu kebijakan berhasil atau gagal.

3. Memenuhi aspek akuntabilitas publik. Dengan melakukan penilaian kinerja suatu kebijakan, maka dapat dipahami sebagai bentuk pertanggungjawaban pemerintah kepada publik sebagai pemilik dana dan mengambil manfaat dari kebijakan dan programpemerintah.

4. Menunjukkan pada stakeholders manfaat suatu kebijakan. Apabila tidak dilakukan evaluasi terhadap sebuah kebijakan, para stakeholder, terutama kelompok sasaran tidak mengetahui secara pasti manfaat dari sebuah kebijakan atauprogram.

5. Agar tidak mengulangi kesalahan yang sama. Pada akhirnya, evaluasi 
kebijakan bermanfaat untuk memberikan masukan bagi proses pengambilan kebijakan yang akan datang agar tidak melakukan kesalahan yang sama.

\section{Konsep Operasional}

Konsep operasional merupakan unsure penelitian yang memberitahukan bagaimana cara mengukur suatu variable (Masri Siangarimbun, 1989:46), sehingga dengan pengukuran ini dapat diketahui, indicator apa saja yang diketahui sebagai pendukungnya untuk dianalisa dari variable tersebut.

Berdasarkan Pedoman Umum tentang Program Keluarga Harapan yaitu Peraturan Menteri Sosial Republik Indonesia Nomor 1 Tahun 2018, maka peneliti menggunakan indikator-indikator untuk melakukan pengukuran kebijakan Program Keluarga Harapan adalah sebagai berikut :

Tabel 3

Indikator Penelitian

\begin{tabular}{|c|c|c|}
\hline \begin{tabular}{|lr}
\multicolumn{2}{|c}{ Variabel } \\
Evaluasi & \\
Pelaksanaan & \\
Program & Keluarga \\
Harapan $\quad$ (PKH) \\
Di & Nagari \\
Tanjuang r Bungo \\
Kecamatan & Suliki \\
Kabupaten & \\
Limapuluh & Kota
\end{tabular} & \multicolumn{2}{|c|}{\begin{tabular}{|l|l|} 
Variabel & Indikator \\
\end{tabular}} \\
\hline \multirow{3}{*}{$\begin{array}{ll}\text { Evaluasi } & \\
\text { Pelaksanaan } & \\
\text { Program } & \text { Keluarga } \\
\text { Harapan } & \text { (PKH) } \\
\text { Di } & \text { Nagari } \\
\text { Tanjuang } & \text { Bungo } \\
\text { Kecamatan } & \text { Suliki } \\
\text { Kabupaten } & \\
\text { Limapuluh } & \text { Kota }\end{array}$} & \begin{tabular}{|l|} 
Indikator \\
1. Efektivitas
\end{tabular} & $\begin{array}{l}\text { Penyaluran Bantuan Sosial Program } \\
\text { Keluarga Harapan ( penyaluran secara } \\
\text { bertahap) } \\
\text { - Pelayanan Uang Tunai } \\
\text { - Pelayanan Kesehatan } \\
\text { - Pelayanan Pendidikan }\end{array}$ \\
\hline & 2. Pemerataan & $\begin{array}{c}\text { PenetapanKeluargaPenerimaManfaat PKH. } \\
\bullet \quad \text { Pendataan Keluarga Penerima Manfaat } \\
\text { (KPM) } \\
\bullet \quad \text { Verifikasi Data Keluarga Penerima } \\
\text { Manfaat (KPM) }\end{array}$ \\
\hline & 3. Responsivitas & $\begin{array}{l}\text { Kewajiban Keluarga Penerima Manfaat PKH } \\
\text { - Pemeriksaan Syarat Keluarga Penerima } \\
\text { - Manfaat } \\
\text { - Kehadiran Sekolah Bagi Anak } \\
\text { - Kehadiran Pemeriksaan Kesehatan }\end{array}$ \\
\hline
\end{tabular}

Sumber :William Dunn

\section{Kerangka Pikiran}

Kemiskinan

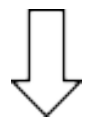

Kebijakan Program Penanggulangan Kemiskinan

Program Keluarga Harapan (PKH) 


\begin{tabular}{|c|c|c|}
\hline $\begin{array}{l}\text { Program } \\
\text { KeluargaHarapan } \\
\text { (PKH) diNagari } \\
\text { Tanjuang Bungo } \\
\text { Kecamatan Suliki } \\
\text { Kabupaten Lima } \\
\text { Puluh Kota. }\end{array}$ & $\square$ & $\begin{array}{c}\text { Sasaran PKH } \\
\text { (KSM/RTSM) }\end{array}$ \\
\hline \multicolumn{3}{|c|}{$\begin{array}{l}\text { Evaluasi Kebijakan Program Keluarga Harapan (PKH) menggunakan indikato } \\
\text { evaluasi kebijakan William Dunn:1. ffektivitas }\end{array}$} \\
\hline \multicolumn{3}{|c|}{ 2. Pemerataan } \\
\hline \multicolumn{3}{|c|}{ 3. Responsivitas } \\
\hline
\end{tabular}

\section{Metode Penelitian}

Menurut Sugiono (2010:91) jenis penelitian yang digunakan dalam penelitian ini adalah penelitian kualitatif yaitu penelitian yang digunakan untuk mengetahui ini variable mandiri baik satu variable atau lebih (independen) tanpa membuat perbandingan atau menghubungkan antara variabel satu dengan variabel yang lainnya. Suatu penelitian yang berusaha menjawab tentang Analisis Pelaksanaan Program Keluarga Harapan Di Nagari Tanjuang Bungo Kecamatan Suliki Kabupaten Limapuluh Kota.

\section{Lokasi dan Waktu Penelitian}

Penelitian ini dilakukan di Nagari Tanjuang Bungo Kecamatan Suliki Kabupaten Lima puluh Kota, tentang Analisis Pelaksanaan Program Keluarga Harapan (PKH). Peneliti memilih daerah ini karena berdasarkan pengamatan penulis, terdapat permasalahan yang perlu penanganan lebih lanjut khususnya tentang pelaksanaan Program Keluarga Harapan (PKH).

\section{Jenis dan Sumber Data}

a) Data Primerdata yang diperoleh langsung dari responden yang merupakan sumber utama dalam penelitian ini, yakni data yang diperolehlangsung dari hasil angket dan wawancara yang ditetapkan.

b) Data Sekunder Yaitu sumber data yang sudah di publikasikan atau diolah oleh instansi yang terkait. Data ini dapat berupa arsip, buku, literature, serta laporan tertulis yang berhubungan dengan penjelasan jenis dan proses pelaksanaan kegiatan- kegiatan Program Keluarga Harapan(PKH).

\section{Subjek Penelitian/ Informan Penelitian}

Subjek Penelitian atau responden adalah orang yang diminta untuk memberikan keterangan tentang suatu fakta atau pendapat. Sebagaimana dijelaskan oleh Arikanto (2013 : 145) subjek penelitian adalah subjek yang dituju untuk diikuti oleh peneliti. Jadi, subjek penelitian ini merupakan sumber informasi yang digali untuk mengungkap fakta-fakta dilapangan. Berdasarkan penjelasan tersebut, maka subjek penelitian digunakan untuk memperoleh informasi yang dibutuhkan secara jelas dan mendalam.

Selanjutnya penentuan subjek penelitian atau responden yang dianggap sebagai key informant dilakukan cara yaitu purposive sampling. Alasan penulis menggunakan dua teknik tersebut karena sumber informant dalam ini terbagi dua pihak, yaitu unit pelaksanaan PKH (UPPKH) Kec. Suliki dan masyarakat yang merupakan Keluarga Penerima Manfaat (KPM).

Dalam penelitian ini istilah yang digunakan untuk subjek penelitian adalah informan. Adapun yang menjadi subjek dalam penelian ini adalah Pendamping Program Keluarga Harapan, Ketua PKH, dan pihak yang kompeten dalam Bantuan Sosial Keluarga Harapan di Nagari Tanjuang Bungo Kecamatan Suliki Kabupaten Limapuluh Kota.

Teknik Purposive Sampling yaitu teknik penentuan sumber data dengan pertimbangan tertentu. Pertimbangan tertentu ini misalnya orang tertentu yang dianggap paling tahu tentang apa yang kita harapkan. Sehingga akan memudahkan peneliti dalam menelusuri situasi yang diteliti Sugiyono (2016:85) 


\section{Hasil dan Pembahasan}

Setelah melakukan peneltian dilapangan (observasi dan wawancara), maka didapatkan dari hasil wawancara dengan memberikan pertanyaan kepada key informan, maka dapat diketahui hasil jawaban dari pertanyaan yang diberikan oleh responden.

Hasil penelitian mengenai Evaluasi Pelakasanaan Program Keluarga Harapan di Nagari Tanjuang Bungo Kecamatan Suliki Kabupaten Limapuluh Kota Tahun 2018 dengan didasarkan pada indikator penelitian. Berdasarkan Pedoman Umum tentang Program Keluarga Harapan yaitu Peraturan Menteri Sosial Republik Indonesia Nomor 1 Tahun 2018 adalah sebagai berikut :
1. Pelaksanaan
Program
KeluargaHarapan
$(\mathrm{PKH})$
Di Nagari

TanjuangBungoKecamatanSulikiKabupatenLimapuluh Kota

a) Efekivitas pelaksanaan Program Keluarga Harapan (PKH). Mengenai penyaluran bantuan PKH diatas dapat diambil kesimpulan, bahwa penyaluran dana $\mathrm{PKH}$ dilakukan secara bertahap, yaitu empat kali penerimaan dalam satu tahun. Proses penyaluran uang PKH berjalan dengan baik karna uangnya masuk kerekening tiap-tiap KPM langsung dari pusat dan KPM sendirilah yang langsung mengambilnya di ATM masing-masing.

b) Pemerataan Penetapan Keluarga Penerima Manfaat Program Keluarga Harapan $(\mathrm{PKH})$. Dari hasil penelitian dapat diambil kesimpulan bahwa dalam penetapan Keluarga Penerima Manfaat di Nagari Tanjuang Bungo sudah sesuai prosedur tetapi belum berjalan dengan baik. Banyak masyarakat yang seharusnya mendapatkan bantuan PKH tetapi tidak mendapatkan bantuan. Dalam penetapan KPM di Nagari Tanjuang Bungo tidak transparansi dan belum mendapatkan kepuasan ditengah-tengah masyarakat

c) Resposivitas dari Keluarga Penerima Manfaat PKH. Penerima manfaat yang menerima bantuan PKH komponen pendidikan harus memenuhi persyaratan kehadiran anak yang sekolah tersebut minimal $85 \%$ dan memeriksakan kesehatan pada fasilitas pelayanan kesehatan sesuai dengan protokol kesehatan. Pendamping akan melakukan pemutakhiran data dalam tiga bulan sekali dan yang tidak memenuhi persyaratan, maka bantuan PKH nya akan di cabut dan di hilangkan. Dapat disimpulkan bahwa pemeriksaan syarat bagi KPM di Nagari Tanjuang Bungo pada komponen Pendidikan dan Kesehatanberjalan dengan baik dan sesuai dengan ketentuan yang berlaku.

2. Faktor-faktor hambatan Dalam Pelaksanaan Program Keluarga Harapan (PKH) Di Nagari Tanjuang Bungo Kecamatan Suliki Kabupaten Lima Puluh Kota.

Ada beberapa faktor yang menjadi penghambat atau kendala dalam pelaksanaan Program PKH di Nagari Tanjuang Bungo. Pertama, tidak adanya pendamping $\mathrm{PKH}$ yang intens mendampingi para peserta $\mathrm{PKH}$ untuk melakukan transformasi perubahan kesejahteraan hidupnya. Karena kondisi tersebut menyebabkan tidak terkontrolnya pengeluaran belanja yang digunakan oleh peserta $\mathrm{PKH}$, sehingga kerap dana PKH dibelanjakan di luar ketentuan yang dipersyaratkan dalam Program PKH. Kedua, jauhnya jarak tempat tinggal pendamping yang berada di luar Wilayah Nagari Tanjuang Bungo, sehingga menyulitkan proses monitoring yang harus dilakukan oleh pendamping. Ketiga, sulitnya melakukan koordinasi di antara Peserta PKH yang dikoordinir dalam kelompok. Hal tersebut disebabkan tempat tinggal peserta dalam kelompok tersebut jaraknya berjauhan dan tidak ada alat komunikasi yang bias menginformasikan jika ada sesuatu hal yang perlu disampaikan kepada Peserta PKH dari Pendamping PKH, sehingga informasi telalu lama sampai ke Peserta PKH. 
JURNAL MANAJEMEN KOMPETEN

VOL. 2 NO. 2 DESEMBER 2019, 66-74 